\title{
Prevalence, Antibiogram and Growth Potential of Salmonella and Shigella in Ethiopia: Implications for Public Health. A Review
}

\author{
Gosa Girma \\ Department of Biology, Stream of Natural Science, Asella College, Asella, Ethiopia \\ E-mail: gosagirma74@gmail.com
}

\begin{abstract}
This article has reviewed researches that obtained from peer-reviewed literatures on Salmonellosis and Shigellosis in different parts of Ethiopia. The prevalence of Salmonella and Shigella, the causative agent for Salmonellosis and Shigellosis, respectively, their antibiogram and growth potential were the main objectives of this review. Foodborne diseases related to unhygienic food handling practices remain a major public health problem across the globe. The problem is severe in developing countries due to limitations in securing optimal hygienic food handling practices. Data shows that an estimated $70 \%$ of cases of diarrheal diseases are associated with the consumption of foods contaminated with pathogenic microorganisms. Among these microorganisms Salmonella and Shigella are the major ones. In most studies of Antibiograms tests, Salmonella and Shigella spp. showed high resistance to the commonly used antibiotics which indicate serious problems in antimicrobial therapy globally, especially in developing countries. In challenge studies, Salmonella and Shigella spp. reached the infective dose within 4 to 24 hours of inoculation, respectively in various food samples. In this review, it is noted that these potentially pathogens are still public health problems. Therefore, there needs health education, frequent monitory and evaluation system of microbiological and antimicrobial surveillance so as to plan intervention strategies for at risk population in the area of water sanitation and hygienic food handling practice to minimize the burden posed by the diseases Salmonellosis and Shigellosis.
\end{abstract}

Keywords: Antibiograms; Diarrheal diseases; Ethiopia; Foodborne diseases; Growth potential; Salmonellosis; Shigellosis.

\section{Introduction}

As far back as the documentation of human history goes, consumption of food unsafe for health and its consequences have been one of man's major health problems. They still remain to be a major public health concern globally. Food- borne diseases are known to be responsible for a large proportion of adult illnesses and deaths; more importantly, as sources of acute diarrheal diseases, they are known to claim the lives of overwhelming numbers of children every day [1].

Globally, Food borne diseases remain a major public health problem. The problem is severe in developing countries due to difficulties in securing optimal hygienic food handling practices. Evidently, in developing countries, up to an estimated $70 \%$ of cases of diarrheal disease are associated with the consumption of contaminated food [1]. Transmission of enteropathogenic bacteria is affected directly or indirectly through objects contaminated with faeces. These include food and water indicating the importance of faecal-oral humanto-human transmission [2].

Furthermore, acute infective diarrhoea and gastroenteritis are major causes of ill health and premature deaths in developing world due, in large part, to the lack of safe drinking water, sanitation and hygiene, as well as poorer overall health and nutritional status. According to the latest available figures, an estimated 2.5 billion people lack improved sanitation facilities, and nearly one billion people do not have access to safe drinking water. These unsanitary environments allow diarrhea causing pathogens to spread more easily [3]. Ranging from mild annoyances during vacations to devastating dehydrating illnesses that can kill within hours, acute gastrointestinal illnesses rank second only to acute upper respiratory illnesses as the most common diseases worldwide. In children less than 5 years old, attack rates range from 2 to 3 illnesses per child per year in developed countries to as high as 10 to 18 illnesses per child per year in developing countries[4].

Nowadays, diarrhoea is one of the most common childhood illnesses, in both developing and developed countries. Estimation by World Health Organization WHO indicates that the world population suffered from 4.6 billion incidences of diarrhea causing 2.2 million deaths in the year 2004. While the disease is rarely a cause of death in developed countries, it is estimated that approximately 1.6 million children die each year from diarrhoea in the developing world. Africa and South Asia are home to more than 80 percent of child deaths due to diarrhoea. In addition, by contributing to malnutrition and thereby reducing resistance to other infectious agents, gastrointestinal illnesses may be indirect factors in a far greater burden of disease $[3,5]$.

All over the world, severe acute bacterial gastroenteritis is caused mainly by Shigella, whereas Salmonella, E. coli (mainly enteropathogenic E. coli, or EPEC, but also enterohemorrhagic

E. coli or EHEC, enteroinvasive E. coli or EIEC and other types), Campylobacter and Vibrio spp. have been shown to play a role in the epidemiology of diarrhea, particularly in certain areas of the globe [6]. 
In past many decades, bacillary dysentery was first differentiated from amoebic dysentery in 1887 and an etiologic agent, Bacillus dysenteriae, was isolated and described by Shiga in 1898. Ontheother hand, Shigella flexneri was originally described by Flexner in 1900. Shigella sonnei was first isolated in 1904, but it was not until 1915 that its pathogenic potential was recognized by Sonne [7]. The consequent painstaking process of epidemiological, physiological, and serological characterization of related dysentery bacilli ended with the recommendations of the 1950. Moreover, Congress of the International Association of Microbiologists Shigella Commission that Shigella be adopted as the generic name and that species subgroups be designated A (Shigella dysenteriae), B (S. flexneri), C (S. boydii), and D (S. sonnei) [8].

Bacteria of the genus Salmonella are widespread and important causes of foodborne infections in man, and are the most frequent etiologic bacterial agents of foodborne disease outbreaks. According to the latest nomenclature, which reflects recent advances in taxonomy [9], the genus Salmonella consists of only two major species: $S$. enterica and $S$. bongori. Serotypes Typhi (S. typhi), S. paratyphi are highly adapted to man. $S$. typhi and $S$. paratyphi have humans as their main reservoir, and enteric fever (typhoid and paratyphoid fever) as their most important clinical manifestation. Enteric fever continues to be an important cause of morbidity and mortality in developing countries. Although primarily intestinal bacteria, salmonellae are widespread in the environment and commonly found in farm effluents, human sewage and in any material subject to faecal contamination. Typhoid fever is a life threatening illness caused by the bacterium Salmonella typhi, and was observed by Karl J. Eberth (1880) in the mesenteric nodes and spleen of fatal cases of typhoid fever.

\section{Food hygiene and food safety practices in Ethiopia}

In these modern days, in which food is usually not consumed immediately following and/or at the site of production, the risks of food-borne diseases are becoming increasingly important; the concern is obviously much more in areas where food storage and preparation safety measures are far below the optimum. Foodborne diseases are common in developing countries including Ethiopia due to the prevailing poor food handling and sanitation practices, inadequate food safety laws, weak regulatory systems, lack of financial resources to invest in safer equipment, and lack of education for food handlers [10]. Likewise, National Hygiene and Sanitation Strategy program [11] reported that in Ethiopia more than 250,000 children die every year from sanitation and hygiene related diseases and about $60 \%$ of the disease burden was related to poor hygiene and sanitation in Ethiopia. Unsafe sources, contaminated raw food items, improper food storage, poor personal hygiene during food preparation, inadequate cooling and reheating of food items and a prolonged time lapse between preparing and consuming food items were mentioned as contributing factors for outbreak of foodborne diseases[12].

Evidently, several studies conducted in different parts of the country showed that the poor sanitary conditions of catering establishments and presence of pathogenic organisms among others such as Salmonella, Staphylococcus aureus, Bacillus cereus, Campylobacter and E.coli, [13,14,15,16,17].

Among the foods intended for humans, those of animal origin tend to be most hazardous unless the principles of food hygiene are employed. Animal products such as meats, fish and their products are generally regarded as high-risk commodity in respect of pathogen contents, natural toxins and other possible contaminants and adulterants [18]. Bacterial contamination of meat products is an unavoidable consequence of meat processing [19]. Several studies noted despite the possibility that data regarding meat borne diseases in Ethiopia are very scarce, a few studies conducted in different parts of the country have shown the public health importance of several bacterial pathogens associated with foods of animal origins [13,16,20,21,22].

\subsection{Salmonellosis}

As report indicated, an American veterinarian Daniel Elmer Salmon, who first isolated Salmonella enterica serotype Choleraesuis from pigs in 1885 [23]. According to research investigations, human infections of Salmonella are divided into typhoid fever, caused by Salmonella typhi and Salmonella paratyphi, and also other clinical syndromes, including diarrhoeal disease, caused by a large number of non-typhoidal salmonella serovars (NTS). Microbiologically, Salmonella species are Gram-negative, flagellated, non-sporeforming, facultative anaerobic rods characterized by $\mathrm{O}, \mathrm{H}$, and VI antigens belongs to the family Enterobacteriaceae. As reported by [24], there are over 2,500 identified serotypes of Salmonella. Salmonella typhi is one of the member and its diagnostic identification can be attained by growth on MacConkey and EMB agars, and the bacteria is strictly non-lactose fermenting. Furthermore, Flowers [25] and D'Aoust [26] stated that Salmonellae form gas while growing in media containing glucose. They are mesophilic, with optimum growth temperature between 35 and $37^{\circ} \mathrm{C}$, but generally have a growth range of 5 to $46^{\circ} \mathrm{C}$. They are killed by pasteurization temperature and time, sensitive to low pH ( 4.5 or below), and do not multiply at water activity (aw) of 0.94 , especially in combination with a $\mathrm{pH}$ of 5.5 and below. The cells survive in frozen and dried states for a long time.

Regarding toxins production in Salmonella, following ingestion of Salmonella cells, the pathogens invade mucosa of the small intestine, proliferate in the epithelial cells, and produce a toxin, resulting in an inflammatory reaction and fluid accumulation in the intestine. The ability of the pathogens to invade and damage the cells is attributed to the production of a thermostable cytotoxic factor. Once inside the epithelial cells, the 
pathogens multiply and produce a thermolabile enterotoxin that is directly related to the secretion of fluid and electrolytes. Production of the enterotoxin is directly related to the growth rate of the pathogens $[27,28]$.

Table 1: Extra-intestinal infectious complications of typhoid fever caused by Salmonella enterica serotype Typhi [29].

\begin{tabular}{|c|c|c|c|}
\hline $\begin{array}{l}\text { Organ } \\
\text { involved }\end{array}$ & Prevalence & Risk factors & Complications \\
\hline $\begin{array}{l}\text { Central } \\
\text { system }\end{array}$ & $3-35 \%$ & $\begin{array}{l}\text { Residence in endemic region, } \\
\text { malignancy, endocarditis, congenital } \\
\text { heart disease, paranasal sinus infections, } \\
\text { pulmonary infections, meningitis, } \\
\text { trauma, surgery, and osteomyelitis of the } \\
\text { skull }\end{array}$ & $\begin{array}{l}\text { Encephalopathy, cerebral oedema, subdural empyema, } \\
\text { cerebral abscess, meningitis, ventriculitis, transient } \\
\text { Parkinsonism, motor neuron disorders, ataxia, } \\
\text { seizures, Guillain-Barre syndrome, psychosis }\end{array}$ \\
\hline $\begin{array}{l}\text { Cardiovascular } \\
\text { system }\end{array}$ & $1-5 \%$ & $\begin{array}{l}\text { Cardiac abnormalities, eg. existing } \\
\text { valvular abnormalities, rheumatic heart } \\
\text { disease, or congenital heart defects }\end{array}$ & $\begin{array}{l}\text { Endocarditis, myocarditis, pericarditis, arteritis, } \\
\text { congestive heart failure }\end{array}$ \\
\hline Pulmonary system & $1-6 \%$ & $\begin{array}{l}\text { Residence in endemic region, past } \\
\text { pulmonary infection, sickle cell } \\
\text { anaemia, alcohol abuse, diabetes, HIV } \\
\text { infection }\end{array}$ & Pneumonia, empyema, bronchopleural fistula \\
\hline Bone and joint & $<1 \%$ & $\begin{array}{l}\text { Sickle cell anaemia, diabetes, systemic } \\
\text { lupus erythematosus, lymphoma, liver } \\
\text { disease, previous surgery or trauma, } \\
\text { those at extremes of age, and } \\
\text { steroid use }\end{array}$ & Osteomyelitis, septic arthritis \\
\hline Hepatobiliary system & $1-26 \%$ & $\begin{array}{l}\text { Residence in endemic region, pyogenic } \\
\text { infections, intravenous drug use, splenic } \\
\text { trauma, HIV, haemoglobinopathy }\end{array}$ & $\begin{array}{l}\text { Cholecystitis, hepatitis, hepatic abscesses, splenic } \\
\text { abscess, peritonitis, paralytic ileus }\end{array}$ \\
\hline Genitourinary system & $<1 \%$ & $\begin{array}{l}\text { Urinary tract, pelvic pathology, and } \\
\text { systemic abnormalities }\end{array}$ & $\begin{array}{l}\text { Urinary tract infection, renal abscess, pelvic infections, } \\
\text { testicular abscess, } \\
\text { prostatitis, epididymitis }\end{array}$ \\
\hline Soft tissue infections & $\begin{array}{l}\text { least cases } \\
\text { reported }\end{array}$ & Diabetes & Psoas abscess, gluteal abscess, cutaneous vasculitis \\
\hline Haematological & $\begin{array}{l}\text { least cases } \\
\text { reported }\end{array}$ & & Haemophagocytosis syndrome \\
\hline
\end{tabular}

Salmonellosis in Ethiopia

Salmonella is the most frequently reported cause of foodborne illness [30]. Foodborne salmonellosis often follows consumption of contaminated animal products, which usually results from infected animals used in food production or from contamination of the carcasses or edible organs [31]. Salmonella infection in meat animals arises from intensive rearing practices and the use of contaminated feeds [20]. Cross-contamination of carcasses with Salmonella can also occur during slaughtering operations [32].Stress associated with transport of animals to abattoir augments shedding of Salmonella by carrier animals and this may contribute to the spread of the organism to other animals in the slaughter plant [33].

According to several reports, Salmonella infection most commonly occurs in countries with poor standards of hygiene in food preparation and handling and where sanitary disposal of sewage is lacking. It mainly occurs in the tropics and sub tropics in Africa, India, Pakistan, South East Asia and South America $[34,35,36,37,38,39]$. Furthermore, studies showed that the widespread occurrence and distribution of Salmonella in Ethiopia. In recent years the number of out breaks of Salmonella in humans has increased considerably in the country. Much more is known now about the extent of foodborne illness and how severe it can be, not just in terms of acute illness, but also in terms of long term consequences. Studies indicated various percentages of Salmonella isolates in towns of Ethiopia. Moreover, high percentages of $S$. typhi isolates have been found to be resistant for antimicrobial agents [40,41,42]. In addition, the very young, elderly and immunocompromized individuals are particularly more susceptible to Salmonella infections at a lower infective dose than healthy adults. This is more important in developing countries such as Ethiopia where HIV/AIDS is highly prevalent and Salmonella is an important opportunistic infection in HIV/AIDS patients [43].

Nevertheless Salmonella populations in different geographical areas or different hosts and environmental niche may undergo different evolutionary change, due to centralization of food production and distribution and population movement, Salmonella strains found in different countries of the world are believed to be clonally related [44]. Salmonella isolates in Ethiopia may have similar phenotypic and genotypic characteristics with isolates elsewhere in the world and non-typhoidal Salmonella enterica infection in children in Ethiopia is a major health problem and is caused by similar serovars to these reported from elsewhere in Africa: $S$. Typhimurium and $S$. Enteritidis[45].

According to [37], in Ethiopia, minced beef is usually used for the preparation of a popular traditional Ethiopian dish known as locally "Kitfo" and most of the time it is consumed raw or medium cooked. The habit of raw meat consumption and the presence of Salmonella in minced beef indicate, in addition to the poor 
hygienic standards in food handling in the country, the presence of great public health hazards of Salmonella.

\subsubsection{Epidemiology}

Typhoid cases are stable with low numbers in developed countries, but nontyphoidal Salmonellosis has increased globally. Evidently, typhoid fever usually causes mortality in 5 to $30 \%$ of typhoid-infected individual in the developing world. Recently, WHO estimates 16 to 17 million cases occur annually, resulting in about 600,000 deaths. The mortality rates differ from region to region, but can be as high as 5 to $7 \%$ despite the use of appropriate antibiotic treatment. On the other hand, nontyphoidal cases account for 1.3 billion cases with 3 million deaths. In the United States, approximately 2 to 4 million cases of Salmonella gastroenteritis occur with about 500 deaths per year. A more accurate figure of salmonellosis is difficult to determine because normally only large outbreaks are investigated whereas sporadic cases are under-reported. Data on salmonellosis are scarce in many countries of Asia, Africa and South and Central America where only 1 to $10 \%$ of cases are reported $[46,47]$.

Typhoid fever is endemic throughout Africa and Asia as well as persists in the Middle East, some eastern and southern European countries and central and South America. In the US and most of Europe, typhoid is predominantly a disease of the returning traveler. Typhoid incidence in endemic areas is typically low in the first few years of life, peaking in school-aged children and young adults and then falling in middle age. Most infections occur in childhood especially in Mekong Delta region of Vietnam and are recognizable although often mild [48]. The most famous outbreak of enteric fever is Typhoid Mary. Mary Mallon, a New York City hired household cook, transmitted typhoid fever to at least 22 individuals causing 3 deaths between 1900 and 1907. After being apprehended by public health officials in 1907, she was isolated for 3 years. Even though she was released with the stipulation that she never cook again, she broke the promise and consequently caused at least 25 more cases of typhoid fever at Manhattan maternity hospital when she was employed as a cook in 1915. She was finally isolated until her death in $1938[49,50]$.

In studies conducted in Jordan on 283 food handlers for potential pathogens in their stool, the rate of isolation of Salmonella was 6\% [51]. Another study showed in two hospitals in Winchester, Southern England that Faecal screening of asymptomatic catering staff demonstrated 12.3\% Salmonella [52]. Prevalence of chronic typhoidal Salmonellae carriers among food vendors in Kumasi, Ghana showed that Typhoidal Salmonellae were isolated from six people out of 258, giving a carriage rate of $2.3 \%$ and three of the Salmonellae isolated were $S$. typhi, and the other three were non-typhoidal Salmonellae [53]. Another study done in Nigeria showed that Salmonella spp. (three S. typhi [5.7\%], three S. enteritidis [5.7\%] and one S. choleraesuis (1.9\%) were recovered from seven (13. $2 \%$ ) of the 53 stool samples processed.

\section{Shigellosis}

Shigella is discovered over 100 years ago by Kiyoshi Shiga, a Japanese scientist, they are Gram-negative, nonmotile, facultative anaerobic, non-spore-forming rods. Its difference from the closely related Escherichia coli is on the basis of pathogenicity, physiology (failure to ferment lactose or decarboxylate lysine) and serology. They are generally catalase positive and oxidase and lactose negative. They ferment sugars, usually without forming gas. The strains grow between 7 and $46^{\circ} \mathrm{C}$, with an optimum at $37^{\circ} \mathrm{C}$ and $\mathrm{pH} 4.5$. The genus is divided into four serogroups with multiple serotypes: Sh. dysenteriae, 12 serotypes; Sh. flexneri, 6 serotypes; Sh. boydii, 18 serotypes; and Sh. sonnei, 1 serotype [54]. Shigellosis is an acute invasive enteric infection; it is clinically manifested by diarrhea that is frequently bloody. Shigellosis is endemic in many developing countries and also occurs in epidemics causing considerable morbidity and mortality. Challenges to control shigellosis include the ease with which Shigella spreads from person to person and the rapidity with which it develops antimicrobial resistance [55].

Table 2: Species and serogroups of Shigella [54].

\begin{tabular}{llll}
\hline Species & Serogroup & Serotypes & \\
\hline S. dysenteriae & $\mathrm{A}$ & 12 & most common, with outbreaks \\
S. flexneri & $\mathrm{B}$ & 6 & \\
S. boydii & $\mathrm{C}$ & 18 & developing countries \\
S. sonnei & $\mathrm{D}$ & 1 & Developed countries $[36,55,56,57,58]$. \\
\hline
\end{tabular}

\subsubsection{Epidemiology}

Annually, there are 165 million cases of shigellosis resulting in 1.1 million deaths in the developing world [56]. The most frequently reported factor associated with the involvement of the infected worker was bare hand contact with the food followed by failure to properly wash hands, inadequate cleaning of processing or preparation equipment or utensils, cross-contamination of ready-to-eat foods by contaminated raw ingredients [57]. During a one-year period, 283 food handlers in Irbid, Jordan were investigated for the presence of potential enteropathogens in their stools. The isolation rate of shigella was $1.4 \%$ [51]

In the study conducted by Desta [58] only one Shigella spp. (0.4\%) was isolated from stool culture of food handlers. Low prevalence of Shigella spp. in food handlers was also reported in some studies elsewhere $(1.3 \%)$ and Ethiopia (3.1\%) [59]. In other studies, no Shigella recovered from stool specimens of food handlers' 
[60]. However, Shigella was the most common bacterial isolated among food handlers in a tertiary care hospital of North India (13.3\%) [44] [61]. Other study in Ethiopia showed that, Shigella dysenteriae and Shigella flexineri have been identified as the species that account for about $80 \%$ of Shigella isolates.

\section{Shigellosis in Ethiopia}

As a global, Shigellosis is human health problem. It is still an important public health problem, especially in developing countries like Ethiopia, where there is substandard hygiene and unsafe water supplies [62,63]. Moreover, Shigella still accounts for a significant proportion of bacillary dysentery in many tropical and subtropical countries [64,65]. It is the most prevalent etiologic agent in childhood diarrhoea in most countries $[66,67]$. In Ethiopia, Shigella dysenteriae and Shigella flexineri have been identified as the species that account for about $80 \%$ of Shigella isolates [63].

Evidently, Shigellosis is a highly infectious disease of world significance. Its prevalence is highest in tropical and subtropical parts of the world where living standards are very low and access to safe and adequate drinking water and proper excreta disposal systems are often limited [68].Diarrheal diseases are the major causes of morbidity and mortality in developing world.

Shigellosis is endemic throughout the world where it is held responsible for some 165 million cases of severe dysentery. The devastating majority of these cases occur in the developing countries [69]. Unlike other secretory diarrhoeas, shigellosis is the result of invasion of the distal small bowel and/or colon by Shigella species [70]. Infections caused by Shigella species are associated with symptoms which range from abdominal pain, cramps, fever, vomiting to bloody mucoid diarrhea [71].

Furthermore, Shigellosis and the emergence of antimicrobial resistant Shigella species is a major health problem in Ethiopia [68]. A few studies conducted previously in the country indicated high rate of resistance to commonly used antimicrobial agents such as ampicillin, tetracycline, cotrimoxazole, chloramphenicol among the isolates [72,73,74,75]. Since the prevalence and pattern of resistance of Shigella species in the country varies from one area to another, updated information on their resistance patterns is very important for the proper selection and use of antimicrobial agents in a setting.

Shigellosis is currently an important health problem around the world, occurring predominantly in children younger than five years old, mainly in developing countries [76]. In Ethiopia, as in other developing countries, shigellosis is a common cause of morbidity and mortality, particularly in children [77]. Its prevalence is high in tropical and sub-tropical regions of the world, where living standards are very low and access to safe and adequate drinking water and proper waste disposal systems are often very limited, even absent [78].

Generally, Shigellosis continues to be an important public health problem since communication in the world has become more frequent. In addition, this disease is difficult to be prevented because only a small number of bacteria are required to cause infection, and it has exhibited steady trends towards multiple drug resistance.

\section{Prevalence of Salmonella and Shigella in Ethiopia}

Recently, many studies have demonstrated the prevalence of Salmonella and Shigella in different parts of Ethiopia. For instance, study conducted in Gonder town showed that Shigella species were isolated from stool samples of four food-handlers (3.1\%) out of 127 food handlers [59]. In the study conducted by Reda et al., [79] 28 (11.5\%) Salmonella and 17 (6.7\%) Shigella were isolated (Table 3). Besides, the prevalence rate of Shigella were also showed in different studies conducted in Ethiopia, a report (9\%) by Ashenafi [80] and $11.7 \%$ isolation rate reported by Asrat et al., [81] at Tikur Anbessa, Ethio-Swedish children's hospital and a report $6.7 \%$ by Reda et al., [79] in Harar. In another study conducted in Jimma relatively smaller prevalence rate 2.3\% [82] were observed. 
Table 3: Prevalence of Salmonella and Shigella and Appearance of diarrhea in patients in Harar, eastern Ethiopia, between Januarys to February 2007 [79].

\begin{tabular}{|c|c|c|c|}
\hline \multirow[t]{2}{*}{ Appearance of diarrhea } & \multicolumn{2}{|c|}{ Organisms isolated } & \multirow[b]{2}{*}{ Total } \\
\hline & Salmonella $(\mathrm{n}, \%)$ & Shigella $(\mathrm{n}, \%)$ & \\
\hline Bloody & $7(25)$ & $1(59)$ & $8(17.8)$ \\
\hline Mucoid & $12(42.8)$ & $9(52.9)$ & $21(46.8)$ \\
\hline Watery & $0(0)$ & $1(5.9)$ & $1(2.2)$ \\
\hline Mucoid and bloody & $9(32.1)$ & $3(17.6)$ & $12(42.8)$ \\
\hline Other & $0(0)$ & $3(17.6)$ & $3(6.7)$ \\
\hline Total & $28(100)$ & 17(100) & $45(100)$ \\
\hline \multicolumn{4}{|c|}{$\begin{array}{l}\text { Moreover, in a cross sectional study conducted in raw milk samples from dairy farms and individual } \\
\text { farmers in Kersa District, Jimma Zone, Ethiopia, indicated that the prevalence of Salmonella spp. in raw milk } \\
\text { was } 20 \% \text { from a total of } 100 \text { samples of raw cow milk [83]. In the recent study conducted on prevalence and } \\
\text { antimicrobial susceptibility patterns of Shigella and Salmonella Species among patients with diarrhea attending } \\
\text { Gondar town health institutions, Northwest Ethiopia by Tesfaye et al., [84] indicated that of the total of } 372 \\
\text { stool cultures, } 17(4.57 \%) \text { Shigella spp. and } 4(1.08 \%) \text { Salmonella spp. were isolated. According to their report, } \\
\text { most commonly isolated strains of Shigella were S. flexneri } 11(64.7 \%) \text { followed by } S \text {. dysenteriae } 3(17.65 \%), S \text {. } \\
\text { boydii } 2(11.77 \%) \text { and } S \text {. sonnei } 1(5.88 \%) \text {. } \\
\text { Table } 4 \text { : The frequency of Shigella and Salmonella species isolated from diarrheic patients attending Gondar } \\
\text { town health institutions, Northwest Ethiopia, February to May } 2014 \text { [84]. }\end{array}$} \\
\hline Shigella spp. & Species groups & Number of isolate & Frequency (\%) \\
\hline & S.flexneri & 11 & 64.7 \\
\hline & S.dysenteriae & 3 & 17.65 \\
\hline & S.boydii & 2 & 11.77 \\
\hline & S.sonnei & 1 & 5.88 \\
\hline & Total & 17 & 80.95 \\
\hline Salmonella spp. & & 4 & 19.05 \\
\hline Total isolates & & 21 & 100 \\
\hline
\end{tabular}

On the other hand, in recent investigation conducted on prevalence of Shigella and Salmonella species among apparently health food handlers of Addis Ababa University student's cafeteria, Addis Ababa, Ethiopia by showed that out of 172 food-handlers screened, stool cultures revealed only six (3.5\%) Salmonella isolates [85]. In their report they noted that these bacterial isolates were identified from food handlers who did not have regular medical checkup. No Shigella species was isolated from any of the stool samples obtained from Food handlers.

Furthermore, in the survey by Mengistu et al., [86] on prevalence and antimicrobial susceptibility patterns of Salmonella serovars and Shigella species in Butajira, central Ethiopia, showed that 40 (10.5\%) Salmonella and 17 (4.5\%) Shigella strains were isolated from 382 patients. The Salmonella strains isolated were $6(15 \%)$ group A (Somatic antigen O, O:2), 5 (12.5\%) each of group B (O:4), D1 (O:9) and D2 (O:9,46) and 3 (7.5\%) group C (O:7/O8) isolates while $16(40 \%)$ could not be typed with the available antisera. Among 17 Shigella species Shigella sonnei founded as $6(35.3 \%)$ followed by Shigella flexneri 5 (29.5\%), Shigella dysenteriae 3 (17.6\%) and Shigella boydii 3 (17.6\%).

Another study conducted in Jimma health center, Jimma, Ethiopia by Beyene and Tasew [87], indicated that from a total stool specimens of 260 diarrheal children collected and examined for the presence of Salmonella and Shigella species, a total of $22(8.5 \%)$ samples were positive for Shigella species, $6(2.3 \%)$ and Salmonella species, $16(6.2 \%)$, respectively.

In the study conducted in Gedo Hospital, West Shoa, Oromia state, Ethiopia by Thirumurugan et al., [88], out of 200 samples, 40 diarrheagenic bacteria were isolated and identified as Shiegella ( $\mathrm{n}=22)$ and Salmonella strains $(\mathrm{n}=18)$.

A cross-sectional study at selected public health facilities in Addis Ababa, Ethiopia on a total of 253 children under 5 with acute diarrhea by Mamuye et al., [89] indicated that among a total of 190 entropathogens isolated $21(9.1 \%)$ was Shigella spp. followed by 10(3.95\%) Salmonella spp.

In addition study conducted elsewhere [90] reviled that from a total of 158 fecal samples collected in under-five children with diarrhea, 11 (7.0\%) Shigella species, and 4 (2.5\%) Salmonella species were isolated, respectively. Moreover, they also noted that the Sero-grouping data indicating that all Shigella isolates were found to be $S$. flexneri whereas Salmonella species were identified as serogroup B (3, 1.9\%) and serogroup A (1, $0.6 \%$ ). 


\subsection{Antibiogram of Salmonella and Shigella}

The increased use of antimicrobial agents in food animal production and human medicine as a means of preventing and treating diseases, as well as promoting growth, is a significant factor in the emergence of antibiotic-resistant bacteria. Therefore, the antibiotic resistance developed as a result of antibiotic use in animal agriculture can be transferred to humans through the food chain. Contamination of food with antibiotic resistant bacteria can be a major threat to public health, causing community outbreaks of infectious diseases. There is also the hazard of therapeutic failure due to the increasing incidence of antimicrobial resistance among Salmonella species[91].

The use of antimicrobial agents in any environment increases selective pressures that may favor the survival of antibiotic resistant strains. Emerging resistance in Salmonella Typhi has been described especially in Africa and Asia and the appearance of Salmonella Typhimurium DT104 in the late 1980s raised main public health concern, thereby threatening the lives of infected individuals [92]. Moreover,[93] stated that multiresistance occurred in Salmonella serotypes including Albany, Anatum, Havana, London and Typhimurium.

The resistance towards the traditional first-line antibiotics such as ampicillin, chloramphenicol and trimethoprim-sulfamethoxazole define multidrug resistance (MDR) in Salmonella enterica [94]. This is of great concern because majority infections with MDR Salmonella are acquired through the consumption of contaminated foods of animal origin such as swines and chicken eggs mentioned that cephalosporin and fluoroquinone-resistant strains of $S$. Choleraesuis have been identified in swines in Taiwan and Thailand. Apart from that, antibiogram testing by [95] revealed Salmonella isolates from chicken eggs in marketing channels and poultry farms in North India were resistant to bacitracin, colistin and polymyxin-B.

Due to the use of antibiotics for the promotion of growth and prevention of disease in food animals, there is an increase of human salmonellosis cases caused by foodborne MDR Salmonella nowadays [96]. This indiscriminate and injudicious use of antibiotics in any setting especially in food animals worldwide should be monitored to reduce the transfer risk of MDR Salmonella to humans. Finally, there is a need of continuous surveillance and sharing of antimicrobial susceptibility data for Salmonella among countries worldwide to ensure the effectiveness of control programmes.

The increasing antimicrobial resistance of Shigella species is a major problem in treating shigellosis. The major route for dissemination of multiple resistances is by horizontal transfer of plasmids carrying antibiotic resistance (Rplasmids). A commonly isolated plasmid carries resistance against ampicillin, chloramphenicol, tetracycline, sulfonamides, streptomycin, and trimethoprim [97]. Ampicillin resistance also is mediated by betalactamases.

High rates of antimicrobial resistance were first reported in Asia, Africa, and South America, but antimicrobial resistance has rapidly spread to developed countries. In India and Bangladesh, 20 percent or more of isolates are resistant to nalidixic acid [98]. Resistance to nalidixic acid also been reported in England and the United States. Antimicrobial resistance is an increasing problem in the United States. Report between 1999 and 2002 indicated that all isolated Shigella were susceptible to ceftriaxone and ciprofloxacin whereas $78 \%$ of isolates were resistant to ampicillin, $46 \%$ to TMP-SMX, $38 \%$ to both ampicillin and TMP-SMX, and 1 percent to nalidixic acid.

In Ethiopia, strains of Shigella that were resistant to many commonly used drugs have been reported in different parts of the country by several studies [82,85]. In the aforementioned Ethiopian study reports, the strains were found to be most commonly resistant to tetracycline $(>80 \%)$, ampicillin $(>65 \%)$, and cotrimoxazole $(>70 \%)$. Multiple drug resistance to ampicillin, chloramphenicol, tetracycline, and streptomycin was also very high in those studies. Belay and his colleagues have reported a strain that was resistant to eight drugs out of the nine antimicrobials they used

In addition in the study elsewhere by [83], Salmonella isolates were showed highly resistance to Nalidixic acid (80\%) followed by Tetracyline and Kanamycin (35\% each) and Amikacin (30\%), Gentamycin, Chloramphenicol and Streptomycin (25\% each) and Ciprofloxacin $(5 \%)$; however, most susceptible to Ciprofloxacin (95\%).

Moreover, in the recent study conducted on prevalence and antimicrobial susceptibility patterns of Shigella and Salmonella Species among patients with diarrhea attending Gondar town health institutions, Northwest Ethiopia by [84] reviled that strains of Shigella species were resistant to ampicilin (94.1\%), tetracycline $(88.2 \%)$, amoxicillin $(88.2 \%)$, but susceptible to norfloxacin $(100 \%)$, and ciprofloxacin $(100 \%)$. Salmonella isolate were also resistant to ampicilin (75\%), amoxicillin (100\%) and tetracycline (75\%), but highly susceptible to norfloxacin $(100 \%)$, chloramphenicol $(100 \%)$ and ciprofloxacin $(100 \%)$. The emergence of antibiotic resistance among Shigella and Salmonella spp. isolates are serious problems in antimicrobial therapy globally, especially in developing countries.

In the study by [85], on anti-microbial susceptibility patterns of Salmonellae Species from food handlers in Addis Ababa University student's cafeteria, all isolates of Salmonella were sensitive to ciprofloxacin $(100 \%)$, amikacin (100\%) and gentamicin (100\%) but resistant to ampicillin (100), clindamycin (100\%), and 
erythromycin $(100 \%)$.

Besides, in study by [86] high frequency of resistance for both Shigella and Salmonella isolates was observed to tetracycline $(82.4 \%, 52.5 \%)$, co-trimoxazole $(76.5 \%, 37.5 \%)$ and ampicillin $(47.1 \%, 60 \%)$, respectively. All isolates were sensitive to ceftriaxone except 6 intermediate level Salmonella isolates. Fifty three percent of Shigella isolates were Multi-Drug Resistant (MDR) ( $\geq 3$ drugs) as compared to 27.5\% of Salmonella isolates.

In the study by [87] in Ethiopia, indicated that Shigella species showed hundred percent resistances to ampicillin, amoxacillin, and cotrimoxazole. All Salmonella isolates (16) were resistant against amoxicillin. All Shigella (6) and Salmonella species were susceptible to ceftriaxone, ciprofloxacin and gentamycin.

In the study by [90], all the four Salmonella species and 11 Shigella species were subjected to antimicrobial susceptibility tests. Accordingly, Shigella flexneri showed high resistance against Amoxicillin (100\%), Erythromycin (90.9\%) and Ampicillin (63.6\%). However, low resistance rate was observed against Gentamicin (27.3\%) and Chloramphenicol (9.1\%) and there was no resistance rate observed against Ciprofloxacin, Nalidixic acid, and Cotrimoxazole.

In research investigation by [88] on antibiotic Susceptibility pattern of Salmonella and Shiegella isolates among diarrheal patients in Gedo Hospital, West Shoa Zone, Oromia State, Ethiopia, among all antibiotics tested, of a 22 Shiegella, 21(95.5\%) Shiegella strain showed the resistance, 1(4.5\%) intermediate to Amoxicillin (AMX) and 17(77.3\%) Shiegella strain showed resistance, 5(22.7\%) intermediate against Tetracycline (TEC). Gentamicin (GEM) showed activity against Shiegella strain compared with other antibiotics tested, 16(72.7\%) were susceptible and 6(27.3\%) were intermediate. The Ciprofloxacin (CIF) 11(50\%) and Cotrimaxazole (COT) 10(45.5\%) showed more or less equal susceptibility pattern, $2(9.1 \%)$ were resistance, 9(40.9\%) were intermediate for Ciprofloxacin (CIF) and 3(13.6\%) were resistance, $9(40.9 \%)$ were intermediate for Co-trimaxazole (COT). Chloramphenicol (CHP) showed 8(36.4\%) resistance, 9(40.9\%) intermediate and $5(22.7 \%)$ were susceptible against Shiegella.

In the recent report [89], the overall resistance rates of isolated Shigella and Salmonella spp were high for Ampicillin $(95.7 \%, 80.0 \%)$ and Augmentin $(91.4 \%, 80)$ respectively. However, high sensitivity was observed among both isolates for Ciprofloxacin $(91.3 \%, 100 \%)$ and Ceftraxion (91.4\%, 100\%). More than 87\% of Shigella species were multiple resistances (resistance for two or more antibiotics). Whereas, $70.0 \%$ for Salmonella species.

Besides the temporal changes in the antibiogram of Shigella species, it is well known that antibiotic susceptibility patterns in Shigella may differ between geographical areas. Such differences are never stable and may change rapidly especially in places where antibiotics

are used excessively (particularly in developing countries) [92]. This warrants for frequent observation on the change in the pattern of antibiogram for this organism.

\subsection{Growth potential of Salmonella and Shigella}

Growth potential is defined as the difference between the population of a microorganism at the end of shelf-life of specific food and its initial population. Although myriad foods can serve as Salmonella sources, meat and meat products, poultry products, and dairy products are significant sources of foodborne pathogen infections in humans. Presence of Salmonella spp. in fresh raw products can vary widely. Frequency usually ranges from 1 to $10 \%$, depending on a range of factors including organism, farming and/or food production practices, and geographical factors [100]. Poultry and egg products have long been recognized as an important Salmonella source in fact, contaminated poultry, eggs and dairy products are probably the most common cause of human Salmonellosis worldwide [101].

Salmonella serotypes can grow and survive on a large number of foods. Their behavior in foods is controlled by a variety of environmental and ecological factors, including water activity (aw), $\mathrm{pH}$, oxidation potential (Eh), chemical composition, the presence of natural or added antimicrobial compounds and storage temperature; as well as processing factors such as heat application and physical handling [102]. For example, optimum $\mathrm{pH}$ for growth in Salmonella is approximately neutral, with values $>9.0$ and $<4.0$ being bactericidal. Minimum growth in some serotypes can occur at $\mathrm{pH} 4.05$ (with $\mathrm{HCl}$ and citric acids), although this minimum can occur at $\mathrm{pH}$ as high as 5.5, depending on the acid used to lower $\mathrm{pH}$ [100]. Growth in Salmonella can continue at temperatures as low as $5.3^{\circ} \mathrm{C}\left(\mathrm{S}\right.$. Heidelberg) and $6.2^{\circ} \mathrm{C}($ S. typhimurium $)$, and temperatures near $45{ }^{\circ} \mathrm{C}$ (temperatures $\geq 45{ }^{\circ} \mathrm{C}$ are bactericidal). In addition, available moisture (aw) inhibits growth at values below 0.94 in neutral $\mathrm{pH}$ media, although higher aw values are required as $\mathrm{pH}$ declines to near the minimum growth values [100].

The determination of growth potential of Salmonella and other food borne pathogens in ready to eat food can be very useful to determine likely threats to food safety [99]. Furthermore, Erku and [103] reported that the potential of Salmonella spp. to grow in weaning foods was also determined on one common factoryproduced infant food and one home-made infant food. In both items, Salmonella increased by approximately 4 
$\log$ units within eight hours and reached counts as high as $\log 8 \mathrm{cfu} / \mathrm{ml}$ within twelve hours. Another study in Ethiopian street vended foods [104], Salmonella typhimurium reached counts $>10^{8} \mathrm{cfu} / \mathrm{g}$ within 24 hours in all the food items tested (Egg sandwich, macaroni and lentil sandwich). Counts increased by about $1 \log$ unit in the first 4 hours and showed a steady growth thereafter.

Study noted that the growth and survival of Shigella spp. in foods is influenced by a number of factors such as temperature, $\mathrm{pH}$, salt content and the presence of preservatives. For example, survival of $S$. flexneri has been shown to increase with: decreasing temperature, increasing $\mathrm{pH}$, and decreasing $\mathrm{NaCl}$ concentration [105].

The temperature range for growth of Shigella spp. is $6-8$ to $45-47^{\circ} \mathrm{C}$. Rapid inactivation occurs at temperatures around $65^{\circ} \mathrm{C}$. In contrast, under frozen $\left(-20^{\circ} \mathrm{C}\right)$ or refrigerated $\left(4^{\circ} \mathrm{C}\right)$ conditions Shigella spp. can survive for extended periods of time [106]. Shigella spp. grows in a pH range of 5-9. Zaika [107] demonstrated that $S$. flexneri is tolerant to acid and can survive at $\mathrm{pH} 4$ for 5 days in broth when incubated at $28^{\circ} \mathrm{C}$. Shigella spp. are better able to survive lower $\mathrm{pH}$ conditions at reduced temperatures, with $S$. flexneri and S. sonnei able to survive for 14 days in tomato juice $(\mathrm{pH} 3.9-4.1)$ and apple juice $(\mathrm{pH} 3.3-3.4)$ stored at $7^{\circ} \mathrm{C}$ [108]. S. flexneri is salt tolerant and is able to grow in media containing $7 \% \mathrm{NaCl}$ at $28^{\circ} \mathrm{C}$ ). It is sensitive to organic acids typically used to preserve food. For example, lactic acid has been demonstrated to be effective at inhibiting $S$. flexneri growth, followed in order by acetic acid, citric acid, malic acid and tartaric acid [109].

On the other hand, Fruits and vegetables can support the growth or survival of Shigella. [102] artificially contaminated fresh cut papaya, jicama, and watermelon with $S$. sonnei, S. flexneri, or S. dysenteriae and within 6 hours at room temperature, growth was observed. [110] inoculated raw cabbage, onion, and green pepper with $S$. flexneri and although counts decreased slightly at $4^{\circ} \mathrm{C}$, survival was observed after 12 days on onion and green pepper, at which time sampling was terminated due to spoilage [110]. Low $\mathrm{pH}$ foods can support survival of Shigella when held at refrigerated temperatures. [109] demonstrated S. sonnei and S. flexneri survival in apple juice ( $\mathrm{pH} 3.3$ to 3.4) and tomato juice ( $\mathrm{pH} 3.9$ to 4.1 ) held at $7^{\circ} \mathrm{C}$ for 14 days.

Besides, prepared foods can also support the survival of Shigella. [111] investigated the growth and survival of $S$. flexneri in boiled rice, lentil soup, milk, cooked beef, cooked fish, mashed potato, mashed brinjal, and raw cucumber. All food samples, except raw cucumber, were autoclaved prior to inoculation. Ten gram or $10 \mathrm{ml}$ samples of each food were inoculated with $10^{5}$ cells of $S$. flexneri, incubated at 5,25 , or $37^{\circ} \mathrm{C}$ and sampled over $72 \mathrm{hr}$. All of the foods tested supported growth up to $10^{8}$ to $10^{10}$ cells per $\mathrm{g}$ or ml within 6 to $18 \mathrm{hr}$ after inoculation at $25^{\circ} \mathrm{C}$ and $37^{\circ} \mathrm{C}[111]$.

Study conducted elsewhere noted that growth of Shigella flexneri was markedly fast in the first 4 hours in "macaroni" compared to "egg sandwich" and "lentil sandwich". Final counts in the food items varied slightly and higher counts were noted in "macaroni" followed by "lentil sandwich. Growth rate in "lentil sandwich" was relatively steadier. Initial inoculum level of the test strain was much lower than that of the other test strains [104]. Shigella is able to survive on produce packaged under vacuum or modified atmosphere. [112] investigated the survival of $S$. sonnei in shredded cabbage packaged under vacuum or in a modified atmosphere of nitrogen and carbon dioxide when stored at room temperature or under refrigeration.

In a microbiological challenge study, the levels of live challenge microorganisms are enumerated at each sampling point. The type of pathogen used determines which enumeration method and media has to be used. If the product does not have a substantial background microflora, non-selective media for direct enumeration may be used. It is practical to analyze the product, including uninoculated control samples, at each or selected sampling points in the study to see how the background microflora is behaving over product shelf life. For example, if a product has a high background microflora, it may suppress the growth of the challenge inoculums. In some cases, this is useful and desirable because the product spoils before pathogens can grow [113].

In summary, the indicated incubation hours, following ingestion of contaminated food containing a sufficient number of Salmonella and Shigella induces disease symptoms such as diarrhea, vomiting and fever [114]. This indicates that food handlers with hygienic problem could play role in food contamination that results health risk.

In several studies, growth of challenged pathogens increased as $\mathrm{pH}$ increased whereas their counts decreased as $\mathrm{pH}$ lowered in general $[115,116]$. On the other hand, the change in $\mathrm{pH}$ could be changing of source of carbon and nitrogen. Some microbial cultures generate enzymes to utilize a new carbon and energy substrate when a small amount of the original carbon and energy substrate is present $[116,117]$. However, $\mathrm{pH}$ is not the only required for the growth microorganisms but also other conducive natures of intrinsic and extrinsic parameters $[118,119]$.

\section{Conclusion}

Salmonellosis and Shigellosis are still global health problems, especially, in developing countries like Ethiopia where poor sanitation, lack of clean water supply and proper sewage disposal system exist. Salmonella and Shigella spp. are the causative agents of diarrheal diseases and the major causes of morbidity and mortality. Moreover, in most studies conducted in the country, they revealed that isolates of Salmonella and Shigella 
showed high rate of drug resistance to the commonly used antibiotics. In challenge studies of Salmonella and Shigella spp., in various food items, they grew to their infective dose within 4 to 24 incubation hours. Following ingestion of contaminated food containing a sufficient number of Salmonella induces disease symptoms. Therefore, for combating the problem posed by these pathogens, measures including health education, using safe waste disposal method, improvement of safe water supply, sanitation facilities and continuous monitoring of microbiological and appropriate usage of antibiotics were suggested.

\section{Acknowledgement}

I am deeply grateful and indebted to all sources of materials used for reviewed this article have been duly acknowledged.

\section{References}

[1] Zeru, K. and Kumie, A. (2007). Sanitary conditions of food establishments in Mekelle town, Tigray, north Ethiopia. Ethiop.J.Health Dev., 21:3-11.

[2] Gashaw, A. Kassu, A., Moges, F., Tiruneh, M. and Huruy, K. (2008). Prevalence of Bacteria and Intestinal Parasites among Food handlers in Gondar Town, Northwest Ethiopia. J Health Popul Nutr.,26:451-455.

[3] UNICEF/WHO. (2009). Diarrhoea: Why children are still dying and what can be done.

[4] Kasper, D.L., Fauci, A.S., Longo, D.L.,Braunwald, E., Hauser, S.L.and Jameson, J.L. (2005). Acute Infectious Diarrheal Diseases and Bacterial Food Poisoning. Harrison's Principles Of Internal Medicine, $16^{\text {th }}$ ed., p. $754-59$.

[5] WHO.(2004). Global burden of disease (GBD), Geneva, Switzerland.

[6] Diniz-Santos, D.R., Santana, J. S., Barretto, J. R., Andrade, M.G. and Silva, L.R. (2005). Acute Diarrhea in Children from Salvador, Bahia, Brazil: BJID, 9 (1):77-83.

[7] Gillespie, S. H and Hawkey, P. M. (2006). Principles and practice of clinical bacteriology $2^{\text {nd }}$ ed.

[8] Hale, T. L. (1991).Genetic Basis of Virulence in Shigella Species. Microbiol. Rev.,55(2): 206-224.

[9] Grimont, P.A.D. and Weill, F.X. 2007. Antigenic Formulae of the Salmonella Serovars, $9^{\text {th }}$ ed., World Health Organization Collaborating Centre for Reference and Research on Salmonella. Institut Pasteur, Paris, France.

[10] WHO. (2004). Regional Office for Africa "Developing and Maintaining Food Safety Control Systems for Africa Current Status and Prospects for Change", Second FAO/WHO Global Forum of Food Safety Regulators, Bangkok, Thailand, Pp. 12- 14.

[11] MoH. (2005).National hygiene and sanitation strategy: To enable 100\% adoption of improved hygiene and sanitation. Federal Democratic Republic of Ethiopia Ministry of Health, Water and sanitation program, pp 5.

[12] Linda du, T. and Irma, V. (2005). Food practices associated with increased risk of bacterial foodborne disease of female students in self-catering residences at the Cape Peninsula University of Technology. $J$. Fam. Ecol. Consum. Sci., p. 33.

[13] Bayleyegn, M., Daniel, A. and Woubit, S. (2003). Sources and distribution of Salmonella serotypes isolated from food animals, slaughterhouse workers and retail meat products in Ethiopia. Ethiopian J Health Dev., 17: 63-70.

[14] Abera, K., Ashebir, M., Aderajew, A., Ayalew, T. and Bedasa, B. (2006). The sanitary condition of food and drink establishments in Awash-Sebat Kilo town, Afar Region, Ethiopian J. Health Dev., 20: 201-203.

[15] Knife, Z. and Abera, K. (2007).Sanitary conditions of food establishments in Mekelle town, Tigray, north Ethiopia. Ethiopian J. Health Dev., 21: 3-11.

[16] Tefera, W., Daniel, A. and Girma, Z. (2009). Prevalence of Thermophilic Campylobacter species in carcasses from sheep and goats in an abattoir in Debre Zeit area, Ethiopia. Ethiopian J. Health Dev., 23: 230

[17] Mekonnen, H., Habtamu, T., Kelali, A. and Shewit, K. (2013). Food safety knowledge and practices of abattoir and butchery shops and the microbial profile of meat in Mekelle City, Ethiopia. Asian Pac J Trop Biomed., 3: 407-412.

[18] Yousuf, A. H. M., Ahmed, M. K., Yeasmin, S., Ahsan, N., Rahman, M. M. and Islam, M. M. (2008). Prevalence of microbial load in shrimp, Penaeus monodon and prawn, Macrobrachium rosenbergii from Bangladesh. World J Agricultural Sci.,4:852 855.

[19] Jones, R., Jonesac. H., Hussein, M., Monique, Z., Gale, B. and John, R. T. (2008). Isolation of lactic acid bacteria with inhibitory activity against pathogens and spoilage organisms associated with fresh meat. Food Microbiol., 25: 228-234.

[20] Ejeta, G., Molla, B., Alemayehu, D. and Muckle, A. (2004). Salmonella serotypes isolated from minced meat beef, mutton and pork in Addis Ababa, Ethiopia. Revue Méd. Vét., 155: 547-551.

[21] Adem, H, Daniel, A. and Girma, Z. (2008). Occurrence of Escherichia coli O157: H7 in retail raw meat products in Ethiopia. J Infec Developing Countries, 2: 389-393. 
[22] Kumar, A., Etsay, K. and Enquabaher, K. (2009). Evaluation of quality of beef produced and sold in parts of Tigrai region of Ethiopia. Trop Animal Health Product. 42: 445-449.

[23] Rabsch, W., Altier, C., Tschape, H., and Baumler, A-J. (2003). Foodborne Salmonella infection. In: Torrence, M.E., and Isaacson, R.E.(eds). Microbial Food Safety in Animal Agriculture. Current Topics. USA, Blackwell Publishing, $97-108$

[24] Foley, S.L. and Lynne,A.M.(2008).Food animal associated Salmonella Challenges: Pathogenesity and antimicrobial resistance.J.Anim.Sci.86:173-187.

[25] Flowers, R.S. (1988).Bacteria associated with foodborne diseases: Shigella and Salmonella, Food Technol., $42(4): 185$.

[26] D'Aoust, J.Y. (1989). Salmonella. In :Foodborne Bacterial Pathogens, Doyel, M.P.(ed.) Marcel Dekker, New York, p.327.

[27] Hornick, R.B., Greisman, S.E., Woodward, T.E., DuPont, H.L., Dawkins, A.T. and Snyder, M.J. (1970). Typhoid fever: pathogenesis and immunologic control. N Engl J Med, 283: 739-746.

[28] Pearson, R.D. and Guerrant, R.L. (2000). Enteric fever and other causes of abdominal pain with fever. Mandell, G.L, Bennett, J.E. and Dolin, R.(eds.). Principles and practice of infectious diseases. Philadelphia, PA: Churchill Livingstone, 1136-1150.

[29] Su, C.P., Chen, Y.C. and Chang, S.C. (2004). Changing characteristics of typhoid fever in Taiwan. $J$ Microbiol Immunol Infect, 37: 109-14.

[30] Birhaneselassie, M. and Williams, D. (2013). A study of Salmonella carriage among asymptomatic foodhandlers in southern Ethiopia. Int. J. Nutr. Food Scien., 2: 243- 245.

[31] Alemayehu, D., Molla, B. and Muckle, A. (2002). Prevalence and antimicrobial resistance of Salmonella isolated from apparently healthy slaughtered cattle in Ethiopia. Trop. Anl. Hlth. Prod., 35: 309-316.

[32] Baird-parker, A. C.(1990): Foodborne salmonellosis. Lancet., 336: 1231-1235.

[33] Isaacson, R. E., Firkins, L. D., Weigel, R. M., Zuckermann, F. A. and Dipietro, J. A., (1999). Effect of transportation and feed withdrawal on shedding of Salmonella Typhimurium among experimentally infected pigs. Am. J. Vet. Res., 60: 1155- 1158.

[34] WHO (1989). Health surveillance and management procedures of food handling workers. Geneva, Pp. 7-36.

[35] Lanata, C. F., Tafur, C., Benavente, L., Gotuzzo, E. and Camllo, C. (1990). Detection of Salmonella typhi carriers in food handlers by Vi serology in Lim, a Peru. Bull Pan Am Health Organ., 24: 177-1782.

[36] Al-Lahham, A. B., Abdu- Saud, M. and Shehabi, A. A. (1990). Prevalence of Salmonella, Shigella and intestinal parasites in food handlers in Irbid, Jordan. J Diarrhoeal Dis Res., 8: 160-162.

[37] Muleta, D. and Ashenafi, M. (2001). Salmonella, Shigella and growth potential of other Foodborne pathogens in Ethiopian street vended foods. East Afr Med., 78: 576-580.

[38] WHO.(2003b). Manual for the laboratory identification and antimicrobial susceptibility testing of bacterial pathogens of public health importance in the developing world. Geneva, Pp. 382-381.

[39] Senthikumar, B. and Prabakaran, G. (2005). Multi drug resistant Salmonella typhi in Asymptomatic Typhoid carriers among food handlers in Namakkal District, Tamil Nadu. Indian. J Med Microbiol., 23: 9294.

[40] Yismaw, G., Negeri, C., Kassu, A., Tiruneh, M. and Mulu, A. (2007). Antimicrobial resistance pattern of Salmonella isolates from Gondar University hosipital, North West Ethiopia. Ethiop Pharm J., 25: 85-90.

[41] Andargie, G., Kassu. A., Moges, F., Tiruneh, M. and Henry, K. (2008). Prevalence of bacteria and intestinal parasites among food handlers in Gondar town, North West Ethiopia. J Health Popul Nutr., 26: 451-455.

[42] Abera, B., Biadegelgen, F. and Bezabih, B. (2010). Prevalence of Salmonella typhi and intestinal parasites among food handlers in Bahir Dar Town, Northwest Ethiopia. Ethiop. J. Health Dev., 24: 46-50.

[43] Catherine, E., Woteki, Sandra, L, Facinoli and Daniel, S. (2001). Keep food safe to eat healthful food must be safe as well as nutritious. $J$. Nutr., 1319: 502-509.

[44] Winokur, P. L., Canton, R., Casellas, J. M. and Legakis, N. (2001). Variations in the prevalence of strains expressing an extended-spectrum beta-lactamase phenotype and characterization of isolates from Europe, the Americas, and the Western Pacific region. Clin Infect Dis., 32: 94-103.

[45] Getenet, B. (2008). Phenotypic and molecular characterizations of Salmonella species in Ethiopia. PhD Thesis, Addis Ababa University, Faculty of Medicine, Addis Ababa, Ethiopia.

[46] Hanes, D. (2003). Nontyphoid Salmonella. In Henegariu, O., Heerema, N. A., Dloughy, S. R., Vance, G. H. and Vogt, P. H. (Eds.). International handbook of foodborne pathogens, p. 137-149. New York: Marcel Dekker, Inc

[47] Hu, L. and Kopecko, D. J. (2003). Typhoid Salmonella. In Millotis, M. D. and Bier, J. W. (Eds.). International handbook of foodborne pathogens, p. 151-165. New York: Marcel Dekker, Inc.

[48] Wray, C. and Davies, R.H. (2003). The epidemiology and ecology of Salmonella in meat producing animals. In: Torrence, M.E. and Isaacson, R.E. (eds). Microbial Food Safety in Animal Agriculture. Current Topics. $1^{\text {st }}$ ed., USA, Blackwell Publishing. Pp $73-82$. 
[49] Scherer, C. A. and Miller, S. I. (2001). Molecular pathogenesis of Salmonella. In Groisman. E. A. (Ed.). Principles of bacterial pathogenesis, p. 265-316. United States of America: Academic Press.

[50] Parry, C. M. (2006). Epidemiological and clinical aspects of human typhoid fever. In Matroeni, P. and Maskell, D. (Eds.). Salmonella infections: Clinical, immunological and molecular aspects, p. 1-18. New York: Cambridge University Press

[51] Al-Lahham, A.B., Abu-Saud, M., Shehabi, A.A. (1990). Prevalence of Salmonella, Shigellaand intestinal parasites in food handlers in Irbid, Jordan. J. Diarrhoeal Dis .Res. 8:160-62.

[52] Dryden, M.S, Keyworth, N., Gabb, R., Stein, K. (1994). Asymptomatic food handlers as the source of nosocomial salmonellosis. J.Hosp. Infect.28:195-208.

[53] Feglo, P.K., Frimpong, E.H., Essel-Ahun, M. (2004). Salmonellae carrier status of food vendors in Kumasi, Ghana. East Afr. Med. J. 81:358-361.

[54] Thomas, L.H. and Gerald, T.K. (2000). Baron's Medical Microbiology.In: shigella, $4^{\text {th }}$ ed.

[55] WHO. (2005). Guidelines for the control of shigellosis, including epidemics due to Shigella dysenteriae type 1

[56] Michael, E., Mohammad, A., Mohammad,Y. (2008). Risk areas and neighborhood-level risk factors for Shigella dysenteriae 1 and Shigella flexneri. Health place, 14:96-105.

[57] Todd,, E.C., Greig ,J.D., Bartleson, C.A. and Michaels, B.S.(2007). Outbreaks where food workers have been implicated in the spread of foodborne disease. Part 3. Factors contributing to outbreaks and description of outbreak categories. J.Food Prot.70:2199-217.

[58] Desta, M.(2010). Prevalence of Salmonella and Shigella among Food Handlers in Catering Establishments in Hawassa University, Hawassa, Ethiopia.Msc thesis

Addis Ababa University. Unpublished

[59] Gashaw, A., Kassu, A., Moges, F., Tiruneh, M., and Huruy, K. (2008). Prevalence of bacteria and intestinal parasites among food handlers in Gondar Town, Northwest Ethiopia. J .Health. Popul. Nutr.26:451-455

[60] Simsek, Z., Koruk, I., Copur, A.C., Gürses, G.(2009). Prevalence of Staphylococcus aureus and intestinal parasites among food handlers in Sanliurfa, Southeastern Anatolia. J Public.Health. Manag .Pract.15:518523.

[61] Khurana, S., Taneja, N., Thapar, R., Sharma, M and Malla N.(2008). Intestinal bacterial and parasitic infections among food handlers in a tertiary care hospital of North India. Trop .Gastroenterol.29:207-209.

[62] Niyogi SK. Shigellosis. J Microbiol.2005;43(2):33-43.

[63] Gerbe-yohannes, A. and Drasar B.S. (1987). Shigella dysentriae and Shigella felexineri; sero type prevalence and seasonal distribution in Addis Ababa Ethiopia 1974-85. Ethiop J Health Dev.,251-85.

[64] Zafar, A., Sabir, N. and Bhutta, Z.A. (2005). Frequency of isolation of shigella serogroups/serotypes and their antimicrobial susceptibility pattern in children from slum areas in Karachi. J Pak Med Assoc., 55(5):184-8

[65] Moez, A.K., Zali, M,R., Dallal, M.M., Hemami, M.R. and Salmanzadhe-Ahrabi. S. (2003). Prevalence and pattern of antimicrobial resistance of Shigella species among patients with acute diarrhoea in Karaj, Tehran, Iran. J Health Popul Nutr., 21(2):96-102.

[66] Khan-Mohammed, Z., Adesiyun, A.A., Swanston, W,H. and Chadee, D.D.(2005). Frequency and characteristics of selected enteropathogens in fecal and rectal specimens from childhood diarrhoea in Trinidad, 1998-2000 Rev Panam Salud Publica., 17(3):170-7.

[67] Geo, F.B., Janet, S.B., Stepehn, A.M, (1998). Jawetz, Melnick, and Adelberg's Medical Microbiology. 21st edition. Appleton \& Lange publishers:224-226.

[68] Abera, G. (2004).Shigellosis in Ethiopia: review of studies conducted since 1974. Ethiop J Biol Sci., 3:191235

[69] Gebre-yohannes, A. and Drasar, B.S. (1987). Shigella dysentriae and Shigella felexineri; sero-type prevalence and seasonal distribution in Addis Ababa Ethiopia 1974 -85. Ethio J Health Dev.,251-56

[70] Bennish, L. M, Harris, R .J., Wojtyniak B J., Struelens M. (1990). Death in shigellosis: incidence and risk factors in hospitalized patients. J infect Dis., 160:500-4

[71] Asghar, U., Saba, N U., Samad, A., Qazilbash, A A.(2002). Identification, Characterization and Antibiotic Susceptibility of Salmonnella and Shigella Species from Blood and Stool samples of Patients .J Med.Sci., 2:85-86.

[72] Afeworki, G., Lirneneh, Y., (1980). Multiple drug resistance within Shigella serogroups. Ethiop Med J., 18:7-11.

[73] Senait, K., Abera, G., Sileshi, L., KidaneMariam, M.(1993). Clinical profile and drug susceptibility pattern of strains isolated from children in Addis Ababa. Ethiop Med J., 37: 19-27.

[74] Roma,B.,Worku,S.,T/Mariam,S.,Langeland,N.(2000). Antimicrobial susceptibility pattern of Shigella isolates in Awassa. Ethiop J of Health Dev., 14:149-154.

[75] Asefa, A., Desta, Z. and Tadesse, I. (1995). Prescribing pattern of antibacterial drugs in a teaching hospital 
in Gondar, Ethiopia. East Afr Med J., 72:56-59.

[76] Paula, M.D., Geimba, M.P., Amaral, P.H and Tondo, E.C. (2010). Antimicrobial resistance and PCRribotyping of Shigella responsible for foodborne outbreaks occurred in southern Brazil. Brazilian Journal of Microbiology, 41: 966-977.

[77] Huruy, K., Kassu, A., Mulu, A., Gebretsadik, S., Andargie, G., Tadesse, T., Birhan, W., Worku, N., Ghebreselassie, D., Belyhun, Y. Yifru, S., Adugna, S. and Tiruneh, M. (2008). High level of antimicrobial resistance of Shigella species isolated from diarrheal patients in University of Gondar Teaching Hospital Gondar, Ethiopia. Pharmacology Online, 2: 328-340.

[78] Tiruneh, M. (2009). Serodiversity and antimicrobial resistance patterns of Shigella isolates at Gondar University Teaching Hospital, Northwest Ethiopia. Japanese Journal of Infectious Disease, 62: 93-97.

[79] Reda, A.A., Seyoum, B., Yimam J. J., Andualem, G., Fiseha S, Jean-Michel Vandeweerd,J J.M.(2011). Antibiotic susceptibility patterns of Salmonella and Shigella isolates in Harar, Eastern Ethiopia. J .Infect. Dis. Immun., 3:134-139

[80] Ashenafi, M. (1998).The prevalence of Salmonella, Shigella and Yersinia enterocolitica in adult diarrhoea out-patients in some hospital of Addis Ababa. Addis Ababa: M.Sc thesis School of graduate studies.

[81] Asrat, D., Hathaway ,A., Ekwall, E. (1999).Studies on enteric campylobacteriosis in TikurAnbessa and Ethio-Swedish children's hospital, Addis Ababa, Ethiopia. Ethiop.Med.J .37:71-84

[82] Beyene, G. and Tasew, H. (2014). Prevalence of intestinal parasite, Shigella and Salmonella species among diarrheal children in Jimma health center, Jimma southwest Ethiopia: Annals of Clinical Microbiology and Antimicrobials, 13:1-7

[83] Tadesse, T. and Dabassa, A. (2012). Prevalence and Antimicrobial Resistance of Salmonella Isolated from Raw Milk Samples Collected from Kersa District, Jimma Zone, Southwest Ethiopia. Journal of Medical Sciences, 12: 224-228.

[84] Tesfaye, A.D., Moges, T.W., Feleke, M. Y., Dagnachew, M.F., Getnet, A. G. (2014). Prevalence and Antimicrobial Susceptibility Patterns of Shigella and Salmonella Species among Patients with Diarrhea Attending Gondar Town Health Institutions, Northwest Ethiopia. Science Journal of Public Health, 2(5).pp. 469-475. doi: 10.11648/j.sjph.20140205.24

[85] Aklilu, A., Kahase, D., Dessalegn, M., Tarekegn, N., Gebremichael, S., Zenebe, S., Desta, K., Mulugeta, G., Mamuye, Y. and Mama, M. (2015). Prevalence of intestinal parasites, salmonella and shigella among apparently health food handlers of Addis Ababa University student's cafeteria, Addis Ababa, Ethiopia. BMC Research Notes, 8:17.

[86] Mengistu, G., Mulugeta G, Lema T, Aseffa A (2014) Prevalence and Antimicrobial Susceptibility Patterns of Salmonella serovars and Shigella species. J Microb Biochem Technol S2: 006. doi:10.4172/19485948.S2-006

[87] Beyene, G. and Tasew, H. (2014). Prevalence of intestinal parasite, Shigella and Salmonella species among diarrheal children in Jimma health center, Jimma southwest Ethiopia: a cross sectional study. Annals of Clinical Microbiology and Antimicrobials, 13:10.

[88] Thirumurugan, G., Yonas, H. and Befikadu, A. (2014). Antibiotic Susceptibility Pattern of Salmonella and Shiegella Isolates Among Diarrheal Patients in Gedo Hospital, West Shoa Zone, Oromia State, Ethiopia. American Journal of Drug Discovery and Development, 4: 194-201.

[89] Mamuye, Y., Metaferia, G., Birhanu A., Desta, K. and Fantaw, S. (2015). Isolation and Antibiotic Susceptibility Patterns of Shigella and Salmonella among Under 5 Children with Acute Diarrhoea: A CrossSectional Study at Selected Public Health Facilities in Addis Ababa, Ethiopia. Clin Microbiol., 4: 186.

[90] Mulatu, G., Beyene, G., and Zeynudin, A. (2014). Prevalence of Shigella, Salmonella and Cmpylobacter Species and Their Susceptibility Patters Among Under Five Children With Diarrhea in Hawassa Town, South Ethiopia. Ethiop J Health Sci., 24(2): 101-108.

[91] Tambekar, D.H., Hirulkar, N.B. and Waghmare, A.S.(2005). MAR indexing to discriminate the source of faecal contamination in drinking water. Nat Environ Poll Tech., 4:525-8.

[92] Montville, T. J. and Matthews, K. R. (2008). Food microbiology: An introduction (2nd ed.). ASM Press, Washington, United States of America.

[93] Van, T. T. H., Moutafis, G., Istivan, T., Tran, L. T. and Coloe, P. J. (2007). Detection of Salmonella spp. in retail raw food samples from Vietnam and characterization of their antibiotic resistance. Appl and Environ .Microbiol .73: 6885-6890.

[94] Crump, J. A. and Mintz, E. D. (2010). Global trends in typhoid and paratyphoid fever. Emerg. Infec. 50: 241-246.

[95] Singh, S., Yadav, A. S., Singh, S. M. and Bharti, P. (2010). Prevalence of Salmonella in chicken eggs collected from poultry farms and marketing channels and their antimicrobial resistance. Food. Resear. Intern.43: 2027-2030.

[96] Yang, B., Qu, D., Zhang, X., Shen, J., Cui, S., Shi, Y., Xi, M., Sheng, M., Zhi, S. and Meng, J. (2010). 
Prevalence and characterization of Salmonella serovars in retail meats of marketplace in Shaanxi, China. Intern.J.of.Food.Microbiol., 141:63-72.

[97] Bhattacharya,S., Khanal, B.,. Bhattarai, N. R and. Das, M .L. (2005).Prevalence of Shigella species and their antimicrobial resistance patterns in Eastern Nepal. J. Health. Popul. Nutr., 23:339-342.

[98] Bennish, M.L., Azad, A.K., Yousefzadeh, D. (1991). Intestinal obstruction during shigellosis: Incidence, clinical features, risk factors and outcome. Gastroenterology .101:626- 632.

[99] Sant'Ana, A.S., Barbosa, M.S., Destro, M.T., Landgraf, M. and Franco, B.D. (2012).Growth potential of Salmonella spp. and Listeria monocytogenes in nine types of ready-to-eat vegetables stored at variable temperature conditions during shelf-life. Int. J. Food Microbiol., 157:52-58.

[100] Harris, L. J., Farber, J. N., Beuchat, L. R., Parish, M. E., Suslow, T. V., Garrett, E. H. \& Busta, F. (2003). Outbreaks Associated with Fresh Produce: Incidence, Growth, and Survival of Pathogens in Fresh and Fresh Cut Produce. Comprehensive Reviews in Food Science and Food Safety, 2: 78-141.

[101] Herikstad, H., Motarjemi, Y. and Tauxe, R.V. (2002). Salmonella surveillance, a global survey of public health serotyping, Epidemiology and Infection,129(1): 1-8.

[102] Escartin, E.F., Ayala, A.C. and Lozano, J.S. (1989). Survival and growth of Salmonella and Shigella on sliced fresh fruit. J. Food Prot., 52: 471-472.

[103] Erku, W.A and Ashenafi, M. (1998). Prevalence of food-borne pathogens and growth potential of Salmonella in weaning foods from Addis Ababa, Ethiopia. East Afric Medi J., 75:215-218.

[104] Muleta, D. and Ashenafi, M. (2001). Salmonella, Shigella and growth potential of other food-borne pathogens in Ethiopian street vended foods East Afr.Med. J . 78:576-580

[105] Zaika, L.L., Phillips, J.G. (2005). Model for the combined effects of temperature, pH and sodium chloride concentration on survival of Shigella flexneri strain 5348 under aerobic conditions. Int. J.of. Food .Microbiol. 101:179-187.

[106] Warren B.R, Parish M.E, Schneider K.R (2006). Shigella as a foodborne pathogen and current methods for detection in food. Critical Reviews in Food Science and Nutrition, 46:551-567.

[107] Zaika, L.L. (2001). The effect of temperature and low $\mathrm{pH}$ on survival of Shigella flexneri in broth. J .of.Food .Protec., 64:1162-1165.

[108] Bagamboula, C., Uyttendaele, M. and Debevere, J. (2002). Acid tolerance of Shigella sonnei and Shigella flexneri. J. Appl. Microbiol., 93: 479-486.

[109] Zaika, L.L. (2002b). Effect of organic aicds and temperature on survival of Shigella flexneri in broth at $\mathrm{pH}$ 4. Journal of Food Protection, 65:1417-1421.

[110] Rafii, F. and Lunsford. P. (1997). Survival and detection of Shigella flexneri in vegetables and commercially prepared salads. J. AOAC Int., 80: 1191-1197.

[111] Islam, M.S., Hasan, M.K. and Khan. S.I. (1993b). Growth and survival of Shigella flexneri in common Bangladeshi foods under various conditions of time and temperature .Appl. Environ. Microbiol., 59: 652654.

[112] Satchell, F.B., Stephenson, P., Andrews, W.H., Estela, L. and Allen. G. (1990). The survival of Shigella sonnei in shredded cabbage. J. Food Prot., 53: 558-562.

[113] Vestergaard, E.M. (2001). Building product confidence with challenge studies. Dairy Food .Environ. Sanit., 21: 206-9.

[114] Feasey, A., Dougan, G., Robert, A., Kingsley, R., Heyderman, S. and Gordon, A. (2012). "Invasive nontyphoidal Salmonella disease: an emerging and neglected tropical disease in Africa". The Lancet, 379: 2489-2499.

[115] Don, S.M.(2008). Optimal Conditions for the Growth of E. coli . www.scribd.com/doc/11337868/OptimalConditions-for-the-Growth-of-E-Coli.Last accessed April 12th 2015.

[116] Lee, Y.K. (2011). Microbial biotechnology principles and applications. 2nd (ed.). World Scientific Publishing Co. Pt. Ltd. Singapore.

[117] Tadesse, G., Ashenafi, M. and Ephraim, E. (2005).Survival of E. coli O157:H7, Staphylococcus aureus, Shigella flexneri and Salmonella spp. in fermenting 'Borde', a traditional Ethiopian beverage. J. Food Contr., 16: 189-196.

[118] Elisa, M. C., Vignolob, G.and Garroa, O. (2003). Modeling lactic acid bacteria growth in vacuumpackaged cooked meat emulsions stored at three temperatures. J. Food Microbiol., 20: 561-566.

[119] Jay, J.M., Loessner, M.J. and Golden, D.A. (2005). Modern food Microbiology. 7th (ed.).Springer science + Business Media, Inc., 233 Springer Street, New York, NY 10013, USA. 
The IISTE is a pioneer in the Open-Access hosting service and academic event management. The aim of the firm is Accelerating Global Knowledge Sharing.

More information about the firm can be found on the homepage:

http://www.iiste.org

\section{CALL FOR JOURNAL PAPERS}

There are more than 30 peer-reviewed academic journals hosted under the hosting platform.

Prospective authors of journals can find the submission instruction on the following page: http://www.iiste.org/journals/ All the journals articles are available online to the readers all over the world without financial, legal, or technical barriers other than those inseparable from gaining access to the internet itself. Paper version of the journals is also available upon request of readers and authors.

\section{MORE RESOURCES}

Book publication information: http://www.iiste.org/book/

Academic conference: http://www.iiste.org/conference/upcoming-conferences-call-for-paper/

\section{IISTE Knowledge Sharing Partners}

EBSCO, Index Copernicus, Ulrich's Periodicals Directory, JournalTOCS, PKP Open Archives Harvester, Bielefeld Academic Search Engine, Elektronische Zeitschriftenbibliothek EZB, Open J-Gate, OCLC WorldCat, Universe Digtial Library, NewJour, Google Scholar

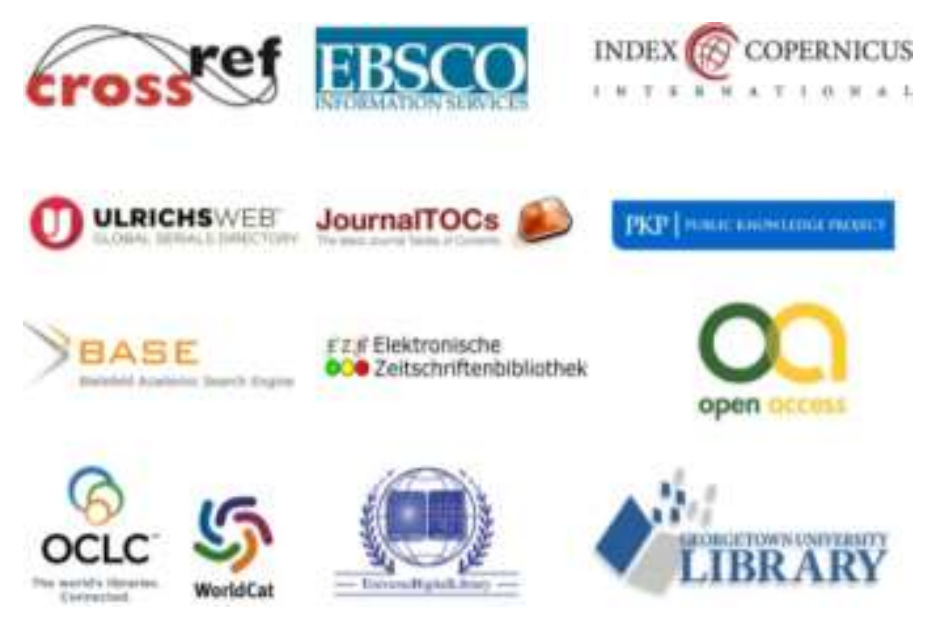

